\title{
Simulation of a competitive business environment: a case study in a Chemical Engineering Program
}

\author{
Domingos Sávio Giordani ${ }^{2 *}$, Elisângela de Jesus Cândido Moraes ${ }^{\mathrm{a}}$, Maria Auxiliadora Motta Barreto ${ }^{\mathrm{a}}$ \\ aniversidade de São Paulo, Lorena, SP, Brazil \\ *dsgiordani@usp.br
}

\begin{abstract}
This paper reports a case study about the experience of two semesters of the discipline Industrial Chemical Processes in School of Engineering of Lorena with the Project-Based Learning approach. Both semesters were based on a set of rules which established the division of the class into groups to submit projects related to the syllabus of the discipline. Two by two, groups competed for an investment which was determined by the rest of the class, who were the investors. Students approved the method and they were excited about the mood of competition. From the first to the second experiences, some modifications in the rules were done, such as the introduction of stakeholder groups, which increased access to the global content of the discipline. The simulation of a business world put forward herein may be readily adapted to other situations and, with minor changes in the ground rules, it is believed that the method can be applied to a wide variety of disciplines of any course.
\end{abstract}

Keywords

Active learning. Engineering education. PBL approaches. Business environment simulation.

How to cite this article: Giordani, D. S., Moraes, E. J. C., \& Barreto, M. A. B. (2017). Simulation of a competitive business environment: a case study in a Chemical Engineering Program. Production, 27(spe), e20162206. http://dx.doi. org/10.1590/0103-6513.220616

\section{Introduction}

In recent years, engineering courses have been facing a double challenge; they must deal with the high velocity of technological changes and, at the same time, they must provide engineers with skills that some years ago were acquired from the professional experience, such as the capacity of teamwork, leadership, communication, and expression. These abilities are being called as "transversal competencies" (Lima et al., 2007) or even "generic competencies", "transferable competencies", "core competencies", "professional competencies" and always refer to those competencies that are beyond technical subjects but are also related to professional practice (Mesquita et al., 2015).

According to Cunha (1998, p. 15), "[...] in engineering curricula there is no room for solving problem situations in groups, proposing new problems with appeals to creativity [...]" and the contents of the disciplines are information that science already has confirmed, never the dilemmas of the present or the empirical knowledge that leads to the future. A large number of disciplines provides students with little time for independent study and extracurricular activities, and when compared to foreign institutions, the direct teacher-student contact time in engineering courses in Brazil can be considered high (Roberto \& Ribeiro, 2008). Also in this sense, Salum (1999) reports that this occurs due to the understanding that the teacher must supply, in the classroom, the lack of laboratories and libraries. This curricular model is negative because excessive hours of direct contact (classes, laboratories, among others) point to a teacher-centered teaching, while the separation of basic disciplines makes the understanding of the importance of science in professional practice more difficult.

It can also be stated that the professional training model based on the transmission and reception of knowledge demonstrates the lack of adequate support in the preparation of the individual for professional 
performance. These conventional models disfavor the development of skills proposed by the professional world: creativity, flexibility, entrepreneurship, and the ability to learn independently (Duch et al., 2001).

Critical studies associating the knowledge retention rate to the teaching method have reported that traditional classes present average rates of retention of only 5\%, while discussion groups, practice by doing and teach others to do respectively show average rates of 50\%, 75\% and 90\% (Singhal et al., 1997, p. 88). Thus, traditional forms of education, although still widely practiced, do not reach the expected role of the XXI century education.

Many innovative methodologies have been tested in recent decades to overcome this separation between what the school offers and what the market demands from professionals. Among them, we can point to Project Based learning (PBL) as one of the most successful. The method stands out for having the student as a central and primary figure in the learning process and for focusing on the student and its performance to acquire the skills defined in the planning of the process (Lima et al., 2007). According to Borges et al. (2011), the key features of the method are the student as the center of the process; the development of the project in tutorial groups and to be an active, collaborative and interdisciplinary process.

Several universities use several PBL formats in their curricula, however, Walsh (2007) states that the key features of PBL are:

- Reliance on problems to drive the curriculum. The problem identifies the starting point and indicates what knowledge will be needed to solve the problem.

- The problems are ill-structured. The problems have more than one right answer with a complexity that prevents a full understanding when first encountered. The problems change in nature as more is discovered about them.

- The students assume significant responsibility for their learning. Lecturers are coaches and facilitators. Most of the learning occurs within the context of groups rather than lectures.

- Performance-based assessment. The assessment is on how the problem is approached, knowledge identified and how the knowledge is brought to bear on solving the problem.

The method can be used in a curricular, partial or hybrid way. The curricular format refers to the implantation of this method throughout the curriculum, already in a partial format, the PBL is implemented in one or more disciplines. In the hybrid format, the PBL occupies, in parallel, one of the positions of the same curriculum (Ribeiro, 2008).

In the PBL, students are challenged by a project that is the starting point of the learning process, whereas in traditional teaching, concepts are initially transmitted and only after its explanation, the obstacles to its application are presented (Duch et al., 2001)

In some cases, challenging students is not a trivial task, especially when the course has a very theoretical content, in this situation teachers are also challenged to use creativity and make the access to the content more interesting. One way that has been widely explored is the use of games and simulation of real life situations, which have been demonstrated to be useful tools to exploit the potential to present complex situations without discouraging students, allowing them to examine important elements of the professional field while they learn the elements of the syllabus (Braghirolli et al., 2016). Furthermore, gaming and simulation environments are excellent learning tools because they can replicate real contexts or even provide training situations that occur in very specific circumstances (Carvalho, 2012).

Also seeking the ability to simultaneously satisfy the demand for knowledge and motivation, Soares et al. (2013) have demonstrated that the competition among groups is positive, because they feel more responsible for the results and more motivated by the expectatancy of winning the competition, while they improve their creativity, as measured by Cascini et al. (2015).

Furthermore, Khrushchev et al. (2015) have used the business games successfully as a tool for simulating various aspects of the professional environment, imitating the industrial process in a simplified reconstruction of real manufacturing situations, showing the potential of these simulations to enhance learning.

In this work, the authors show how two consecutive experiences, based on some PBL principals, were used to simulate a competitive business environment with the students of a discipline called Industrial Chemical Processes aiming at the same time to promote the learning of the elements of the course syllabus and the acquisition of transversal competencies needed to the engineering professionals. 


\section{Context of the study}

This study arose from the experience of the authors in the implementation of a new approach to conducting a discipline whose content is quite theoretical. It is, therefore, an account of the observations and perceptions of the teachers during two consecutive semesters of its application.

\subsection{The discipline}

The discipline used in this experience is called Industrial Chemical Processes 11. It is positioned at the eighth semester of a ten semesters syllabus of the Chemical Engineering course at School of Engineering of Lorena, a unit of the University of São Paulo in Brazil. It is not a discipline of the main core of the syllabus, but it is important because it improves the overview that the student has in chemical engineering knowledge areas.

The program of the discipline consists of six themes: pulp and paper industries, sugar industry, alcohol industry, biotechnology industries, technology of fats and oils and manufacture of soaps and detergents. Its objective is to provide students with a current view of industrial processes that use chemical or biochemical conversion as a route of the transformation of raw materials into products.

Up to 2014, the discipline was taught by traditional teaching approach that is, the teacher prepared lessons and passed the information to the students in lectures with slides. They were assessed through two written tests.

\subsection{Importance of changing teaching approaches}

Competence can be understood, in the broad sense, as knowledge in action (Moreno, 2006). It involves, therefore, a combination of knowledge (knowing what to do), skills (knowing how to do, being able to) and attitudes (being motivated to do, interacting with everyone appropriately to achieve the goal). The importance of this concept to the areas of education and work lies in the fact that what is expected of a good professional is not only theoretical or technical knowledge about a subject but rather that he/she demonstrates competence, that is, knowledge in real-life situations, knowing how to adjust to different contexts.

Transversal competencies can be understood as attitudes, capacities and abilities of the individual, which contribute to efficient performance in different work situations, and they can be transferable from one context to another throughout life. Some examples are the ability to work in a team, responsibility and communication. They differ, therefore, from technical competencies that relate to performance in specific tasks of each profession. Transversal competencies are therefore elements that favor good performance in the world of work, as they help individuals cope better with different types of work situations and facilitate the application of their technical skills (Moreno, 2006).

Employers value in their employees many skills that are not present in higher education curricula (Frame \& Canter, 2002), therefore it is crucial to any graduate course to provide such skills to their students.

Due to a large number of definitions of transversal competencies, for this work, it was used a model described by Moreno (2006), which applies to the context of higher education. This model specifies seven transversal competencies (autonomy, initiative, problem-solving, teamwork, work organization, responsibility at work and interpersonal relations).

\subsection{The new proposal}

The change in the teaching method goes beyond the need to provide transversal skills to the students. In several informal surveys conducted at the School in the latest semesters on teaching and on the learning process, it is predominant the students' opinion that they would like to have more participatory and dynamic classes and that they no longer tolerate the classes they need to listen to lectures, study related texts and answer questions about them. They feel like being trained for the test and not for life.

In this context, and taking advantage of the type of discipline involved, a process of change that began with one teacher and soon spread to two teachers was initiated.

The new proposal to the course is based on a PBL approach, which was adapted to working conditions, cultural values and language, as Kolmos et al. (2009) advised in their work. So, using the Kolmos' frame of Models of Problem-Based Learning, we proposed a mixture of Model 11 with Model IV, since students were encouraged to solve real problems to undertake practical action at the same time as they were independent thinkers with a critical stance in trans-disciplinary learning. 
Thus, the classes were divided into groups. Each two groups were supposed to work on the same theme, and they had as a project the preparation of a presentation about the subject, and they competed against each other. The group should act as if it was a start-up company; the rest of the class should act as if they were investors, who should define what "company" would receive more investment.

An example of a schedule of the semester is shown in Figure 1. The groups were coded by a number (quantity of groups) and a letter (the theme explored). Thus, the group 1A and the group 7A work on the same subject and compete against each other.

\begin{tabular}{|c|c|c|c|c|c|c|c|c|c|c|c|c|c|c|c|c|}
\hline GROUPS & Week & 1 Week 2 & Week 3 & Week 4 & Week 5 & 5 Week 6 & Week 7 & Week 8 & Week 9 & Week 10 & Week 11 & Week 12 & Week 13 & Week 14 & Week 15 & Week 16 \\
\hline $1 \mathrm{~A}$ & & & & & & & & & & & & & & & & \\
\hline $2 \mathrm{~B}$ & & & & & & & & & & & & & & & & \\
\hline $3 C$ & & & & & & & & & & & & & & & & \\
\hline $4 \mathrm{D}$ & & & & & & & & & & & & & & & & \\
\hline $5 E$ & & & & & & & & & & & & & & & & \\
\hline $6 \mathrm{~F}$ & & & & & & & & & & & & & & & & \\
\hline $7 \mathrm{~A}$ & & & & & & & & & & & & & & & & \\
\hline $8 B$ & & & & & & & & & & & & & & & & \\
\hline $9 \mathrm{C}$ & & & & & & & & & & & & & & & & \\
\hline $10 D$ & & & & & & & & & & & & & & & & \\
\hline $11 \mathrm{E}$ & & & & & & & & & & & & & & & & \\
\hline $12 \mathrm{~F}$ & & & & & & & & & & & & & & & & \\
\hline
\end{tabular}

Figure 1. Schedule of the semester of 2014.

The basic rules of the "game" were announced in the first week, after a motivational speech on the PBL method and its benefits to the learning process. In the second week of the schedule, the students attended a lecture about project management and had to prepare a basic project to attain their objectives; this project should be presented in the fourth week, after the third one, when they learned about presentations.

\subsection{The rules}

The initial idea of this methodology was created by a single teacher, concerned with the need to create a more favorable teaching environment and to develop extracurricular competencies in the students. The work reported here is an evolution of the initial idea, which was developed by two teachers in the semesters following the creation. The teachers established rules that regulated the experiments, they have been compiled on 12 items, as described in Table 1.

\subsection{The composition of individual scores}

Also on the first day of the course, the rule of composition of individual scores was shown to the students. Thus everyone knew how they would be assessed and how their score in the discipline would be calculated.

The students had two grades in the semester, corresponding to the grades of the two written tests of the regular rule of the discipline. These grades were called as $\mathrm{P}_{1}$ and $\mathrm{P}_{2}$ and were calculated according to the Equation 1:

$$
P_{x}=G_{\text {invest }}+G_{\text {att }}+G_{\text {peer }}+G_{\text {prof }}
$$

Where $\mathrm{G}_{\text {invest }}$ is the average of the investment received by the group, $\mathrm{G}_{\text {att }}$ is a grade proportional to the attendance to presentations, $\mathrm{G}_{\text {peer }}$ is the peer assessment of the student (attributed by the group) and $\mathrm{G}_{\text {prof }}$ is the grade assigned to the group by the teacher, corresponding to the evaluation made by the teacher about the scope of the theme and the depth with which it was approached. In fact, this is the teacher's assessment of the learning provided by the presentation. The rule for each grade is shown in the Table 2 .

As it can be seen in Table 2, if all the grades are the highest, the sum is 12, but the maximum score at the University is 10; this was intentional, because in case both opponent groups were excellent and balanced and had their investment divided as 50\% for each, the grade of the teachers could compensate a possibly unfair grade, making possible the highest score (10) to the student or group. 
Table 1. The main rules.

\begin{tabular}{|c|c|}
\hline 1 & $\begin{array}{l}\text { The course will be based on a PBL approach. Thus, all program content will be viewed by students within a scheme in which you } \\
\text { must "get your hands dirty." }\end{array}$ \\
\hline 2 & The central idea is that there will be working groups that will act as start-up companies that will present projects to investors. \\
\hline 3 & The groups may be organized with the following positions: Manager, reporter, spokesman, and co-workers. \\
\hline \multirow{7}{*}{4} & Each two groups will work on one of the following themes: \\
\hline & 1. pulp and paper industries \\
\hline & 2. sugar industry \\
\hline & 3. alcohol industry \\
\hline & 4. biotechnology industries \\
\hline & 5. technology of fats and oils \\
\hline & 6. manufacture of soaps and detergents \\
\hline 5 & The groups compete with each other in pairs, that is, a group has as an opponent the one who works on the same theme. \\
\hline 6 & $\begin{array}{l}\text { There will be a presentation schedule, divided into two blocks. In the first block, each group will present their area of knowledge, } \\
\text { in the second; it will present a specific problem and its innovative solution for it. }\end{array}$ \\
\hline 7 & $\begin{array}{l}\text { Each group should prepare an "investment proposal" in its area of expertise to convince investors to allocate "funds" to the } \\
\text { project. Since investors know nothing about the matter, in the first presentation the group must let them know the context of the } \\
\text { subject; then, in the second presentation, the group must present an innovative idea to be implemented, containing a study of } \\
\text { technical and economic feasibility and possible environmental impacts. }\end{array}$ \\
\hline 8 & $\begin{array}{l}\text { The investors are the students (except, of course, the assessed team and its opponent) so that the students decide what } \\
\text { percentage of the available "funds" will be allocated to each project. The number of available resources is imaginary and should } \\
\text { be set in percentage terms for each team. }\end{array}$ \\
\hline \multirow{4}{*}{9} & Each presentation must include: \\
\hline & 1. A text, delivered at the presentation day in PDF format; \\
\hline & 2. A slideshow of up to 15 minutes; \\
\hline & $\begin{array}{l}\text { After each presentation, the opposing team will do a question to the presenting team. The team has five minutes to formulate } \\
\text { and present the answer. }\end{array}$ \\
\hline 10 & $\begin{array}{l}\text { In the week between the two blocks of presentation, the groups may reorganize changing positions of each member. Each group } \\
\text { may, only in this week, dismiss a member of the group, which will be "unemployed" and may get "job" in another group (if there } \\
\text { is a place there). The members of the group decide by voting whether any members will be admitted or dismissed. A member of } \\
\text { the group may also fire himself, which also leads him to the condition of "unemployed". }\end{array}$ \\
\hline 11 & $\begin{array}{l}\text { Students who remain in the condition of "unemployed" will have its grades calculated by the normal rule of assessment of the } \\
\text { discipline, that is, two written tests, made in the middle and at the end of the semester. The subject of the tests will correspond } \\
\text { to the content of the presentations made until the evaluation date. }\end{array}$ \\
\hline 12 & Any additional demands in order to enable the course to be properly applied will be adjusted during the semester by the teachers. \\
\hline
\end{tabular}

Table 2. The rule of composition of individual scores.

\begin{tabular}{cc}
\hline Grade & Points \\
\hline Investment (Group) $-\mathrm{G}_{\text {invest }}$ & From 0 to 4 points (proportional to the investment) \\
Attendance in presentations (Individual) $-\mathrm{G}_{\text {att }}$ & Up to 2 points (proportional to the amount of attendance) \\
Peer-assessment in the group (Individual) $-\mathrm{G}_{\text {per }}$ & Up to 2 points (specific rule) \\
Overall score - Teachers (Group) $-\mathrm{G}_{\text {prof }}$ & From 0 to 4 points \\
\hline
\end{tabular}

Note. The sum cannot exceed 10 !

After each presentation, all the "investors" received a card with statements about the quality of presentation, with responses scaled between strongly disagree and fully agree, according to the likert scale, as it can be seen in the Figure 2. They had to fulfill the card with the investment grade, in percentage.

The peer-assessment in the group had a specific rule. The group should attribute a grade for each member, according to the possible notes that are described in Table 3, so that the sum of the grades of the group result in zero. Each grade corresponds to points that contribute to the score of each student. The idea was to force the group to rank the quality of participation of each member.

All the control of the process was implemented using Excel ${ }^{\circledR}$ worksheets where the teachers noted every week, the presence, the investment given by each student to the groups and his grade to each group. At the end of each block of presentation, they collected the peer assessment grades, and the $P_{x}$ grade was calculated and published. 


\begin{tabular}{|c|c|c|c|c|c|}
\hline Statement & $\begin{array}{l}\text { Strongly } \\
\text { disagree }\end{array}$ & Disagree & $\begin{array}{c}\text { Neither } \\
\text { disagree } \\
\text { nor } \\
\text { agree }\end{array}$ & Agree & $\begin{array}{l}\text { Strongly } \\
\text { agree }\end{array}$ \\
\hline \multicolumn{6}{|l|}{ The presentation was appropriate to the subject } \\
\hline \multicolumn{6}{|l|}{$\begin{array}{l}\text { Presenters demonstrated to have adequately } \\
\text { prepared to pass on their knowledge to you }\end{array}$} \\
\hline \multicolumn{6}{|l|}{ The topics of the presentation were well organized } \\
\hline \multicolumn{6}{|l|}{ The oral presentation was clear } \\
\hline \multicolumn{6}{|l|}{$\begin{array}{l}\text { The presenter made good use computational and } \\
\text { audio-visual resources available }\end{array}$} \\
\hline \multicolumn{6}{|l|}{$\begin{array}{l}\text { The presenter made good use of time for the } \\
\text { presentation }\end{array}$} \\
\hline \multicolumn{6}{|l|}{$\begin{array}{l}\text { In the question section, the group presented their } \\
\text { arguments clearly and rationally }\end{array}$} \\
\hline \multicolumn{6}{|l|}{ The presentation contributed to your learning } \\
\hline \multicolumn{6}{|l|}{$\begin{array}{l}\text { The presentation sparked your interest to study } \\
\text { more about it }\end{array}$} \\
\hline \multicolumn{6}{|l|}{$\begin{array}{l}\text { The presentation convinced you to invest in this } \\
\text { company }\end{array}$} \\
\hline $\begin{array}{l}\text { Knowing that there are two companies presenting } \\
\text { on the same subject and you should invest all your } \\
\text { resources in both and, based on your answers } \\
\text { above, what percentage of your resources you } \\
\text { decided to invest in this company? }\end{array}$ & \multicolumn{5}{|l|}{$\begin{array}{l}\text { My Name: } \\
\text { My Group: }\end{array}$} \\
\hline
\end{tabular}

Figure 2. Evaluation and investment card.

Table 3. Range of the possible grades in peer-assessment.

\begin{tabular}{cc}
\hline Possible Grades & Points \\
\hline-2 & 0 \\
-1 & 0.5 \\
0 & 1 \\
1 & 1.5 \\
2 & 2 \\
\hline
\end{tabular}

\section{Methodological approach}

This work is a case study, classified as single-case and explanatory, which according to Yin (2010), is a trial to clarify the reasons to take a set of decisions in a process, how they were implemented and with what results achieved. To Nascimento (2002), its results cannot be applied to others, although it can be used as a model for similar applications.

The universe of the research was limited to two classes of the same discipline, in which the proposed approach was applied in two consecutive years, 2014 and 2015. Classes had 66 and 24 students, respectively.

There were some differences between the first and the second experiments. The first difference is related to the organization of groups in terms of the number of students in two classes. In 2014, the course program was organized in six topics, according to the item 4 of Table 1, and in 2015 four topics were used. Thus, in 2014, there were twelve groups and in 2015 only eight.

There were also some changes in the starting rules, as the teachers felt, based on their experiences, that they needed to be improved. The modifications in the rules were elaborated between the two years and obviously implemented in the second experiment, as it will be discussed in section 4.3.

The authors emphasized the practical application of PBL and used a survey to have a feedback from students about the methodology, so it was possible to evaluate the acceptance of the approach. 
To be comparable, the same survey was applied to both classes and consisted of statements to be classified using the Likert scale. The statements are described in the Table 4.

Table 4. Statements to be evaluated by the students.

\begin{tabular}{cl}
\hline & \multicolumn{1}{c}{ Statements } \\
\hline 1 & The methodology used in this course is innovative \\
2 & 1 think the learning method has brought losses to my learning \\
3 & This way used in teaching the discipline was more motivating than the traditional way \\
4 & This way of teaching used in the course resulted in a higher workload than the traditional way \\
5 & 1 learned very well the subjects related to my group \\
6 & 1 managed to learn very well the topics concerned to the other groups \\
7 & 1 consider that the criteria for evaluation (grades) were righteous \\
8 & There have been many attempts to circumvent the rules by the students \\
9 & 1 wish more disciplines were taught this way \\
10 & The competitive environment contributes to motivating the learning \\
\hline
\end{tabular}

The transversal competencies acquired by the students are not easily measurable objectively, so the teachers had a meeting after each class to evaluate and discuss their comments regarding the observed evolutions. Thus, competencies expected to be developed in Higher Education Programs could have their evolution noted with the aim of, at the end of the work, being gathered to provide an overview of the whole process.

Regarding the ethical aspects involved in these observations (Barnard, 1998), all the students were informed in the first day that they would be observed by the teachers and that those observations would be used to develop new teaching approaches. All of them consented to be voluntary to the "experiments".

\section{Results and discussion}

\subsection{The presentation environment}

In the fifth week of the semester, the presentations were started. The first significant behavioral point observed was the language used by the presenters; they have immediately grasped the idea of the business environment, and they have addressed to the class as if they were speaking to possible interested parties in their businesses, not as speaking to classmates, using a more formal language than that used colloquially.

The competition environment has brought seriousness to the process. It was observed that most teams had worked well in their presentations, trying to convince colleagues that their "companies" knew enough about the subject they worked.

The presence in the classes was high, averaging 90\% attendance at all sessions. Obviously, a lot of this was because part of the grade (up to two points) was proportional to the presence, but the active participation of students in presentations could be observed on several occasions, with students asking questions and comments to presentations that did not concern with their specific themes.

\subsection{Corrections in some rules during the first experiment}

Over the first few weeks of work, some corrections had to be made in the rules to adjust the methodology to the proposed objectives of the course. Among them, stand out the following:

- Each week, two groups presented their work based on the fundamentals of their theme, and then the opponent team formulated their question to the group. Although the objective of this procedure was to show the "investors" the knowledge of the group on its subject, some opponent teams started to formulate questions as real traps, aiming to put the presenters in a difficult situation. Although this is a case that will invariably be found in their professional lives, it was decided to monitor such teams, so the teachers started to judge questions before they were proposed and when they observed the destructive intention in some question, they asked the group to reformulate it; 
- After a few weeks of work, it could be noticed some interesting facts on the behavior of students. The main fact to be reported is that about the popularity of some individuals, who began lobbying for more invest in their companies, regardless of the presentation quality.

This fact could be observed when the teachers noticed a discrepancy between the grade they had attributed to a group and the investment obtained by this group that had clearly presented a job with lower quality. To eliminate the suspicion, the teachers called some students to talk privately and asked if there was anything abnormal in the allocation of investment for that specific group. Then some students revealed that a member of the team, a very charismatic person, had asked colleagues to invest more in his group.

Despite considering a serious fact, the case was seen as caused by the competitive environment that has been created, which has a whole positive aspect for promoting the quality of work, but, on the other hand, it also has a downside which can lead the unethical actions like this. Unethical practices are frequently performed by many students and are not always detected by the teachers, such as the cheating on the tests. Since understanding ethical implications of project decisions is recognized as an important attribute, this event was seen by teachers as an excellent opportunity to address the need for ethical action in the labor market, in line with the primary objective to prepare fully trained engineers. The main conclusion, as seen in other experiments (Jollands et al., 2012), was that such ethical deviations were not the rule, but exceptions judged to be scandalous by the majority of the class.

The means employed to correct this problem was to introduce an adjustment factor in the investment grade for each student. This element was called "payback investment factor" and was calculated according to the success of their investments in groups who obtained higher average investments, i.e., if the student systematically invested in groups that had low average investment, the factor would be less than one and his investment note would decrease slightly, but if the student invested in the best-evaluated groups, the factor would be greater than one and his investment note would increase slightly. So, Equation 1 was replaced by Equation 2. After this change of rule and the talk about ethics, no more discrepancies were observed between the average class investments and teachers' grades.

$$
P_{x}=G_{\text {invest }} \times f_{\text {payback }}+G_{\text {att }}+G_{\text {peer }}+G_{\text {prof }}
$$

Where $\mathrm{f}_{\text {payback }}$ is the payback investment factor, which can be calculated by Equation 3:

$$
\mathrm{f}_{\text {payback }}=\frac{\sum_{1}^{\mathrm{n}}\left(\mathrm{I}_{\mathrm{s}_{\mathrm{n}}} \times \mathrm{I}_{\mathrm{e}_{\mathrm{n}}}\right)}{\mathrm{n}}
$$

Where $\mathrm{n}$ is the number of groups in which the student invested; $l_{\mathrm{s}}$ is the lnvestment done by the student in the group $\mathrm{n}$ and $l_{\mathrm{e}}$ is the average lnvestment reached by the group $\mathrm{n}$ in one presentation.

- Another correction that was necessary was related to the peer assessment grade. At the end of the first block of presentations, all the groups were instructed to rank their members according to the rule of peer assessment described in Table 3. But, 10 of 12 groups attributed the grade zero to everyone, what did not break the rule, but neither ranked the quality of the participation of each group member. So, for the next assessment, it was prohibited zero attribution for all group members.

\subsection{New rules added to the second experiment}

Based on the experience gathered in the first experiment, some changes were implemented in the rules to improve the system.

- The first and most important change was the creation of the stakeholder groups. One of the problems pointed out by the students in the first experience was that the groups were too restricted to the study of their work issues. To overcome that, the figure of the stakeholder group was established, and the interests of this group were in some way linked to the success of another group. Thus, the stakeholder group should help another group on their work and, in the day of their presentation, interact with the presenters to enrich the knowledge transmitted by them. The compensation for the work of stakeholder appears as an extra grade that can be added to the score assigned by teachers to their group. This extra grade, called $G_{\text {stk }}$, is the difference between the score achieved by 
the group supported by the stakeholders and their notes, whenever this difference is positive. So, a new term is added to the Equation 2, that becomes the Equation 4:

$$
P_{x}=G_{\text {invest }} \times f_{\text {payback }}+G_{\text {att }}+G_{\text {peer }}+G_{\text {prof }}+G_{\text {stk }}
$$

- A change was also made in the rule number 9 of Table 1 , the presentation time has been increased to 25 minutes and the question asked by the opponent group was eliminated, being replaced by 10 minutes for the stakeholder group to present its contribution to the issue presented, after that, the questions were open to the entire class;

- A third change was made. A questionnaire containing multiple choice questions on the subject of that week was applied to measure the knowledge acquired by students in each topic presented by the groups, before each presentation of the first block. The students had 15 minutes to answer it, and they were told they did not need to be identified and that the result of that test would not influence in their grades. After the second presentation of each group in the second block of presentations, the same questionnaire was distributed and answered with the same instructions. The idea was to measure the increase in knowledge after the briefings. Unfortunately, presumably, because the students did not identify themselves and the results did not change their grades, it was noted that many students did not answer the questionnaire seriously, especially in the second round. With a careful analysis of responses, those considered "not serious" (all responses in the same letter, for example) have been eliminated, and it could be seen an average increase of $45 \%$ in the success rate of replies. Nevertheless, this result shows no statistical confidence and cannot be taken into consideration. For the next experiment, a new change in the rules is already established: students should be identified when answering these questionnaires. Also, a way to take the increase in knowledge of the students into account on the composition of the final grade is being planned.

\subsection{Transversal competencies observed}

By working in groups with their organizational structure and leaders, students had the opportunity to exercise leadership and communication skills, sense of organization and responsibility for meeting schedules. The creativity and proactivity are other skills that have come with the PBL since learning was focussed on the student, who became the leading actor in the process of acquisition and manipulation of information. With the presentations to the classmates, students exercised the ability to assemble a clear and succinct presentation, besides the control of time, a great difficult for those who are still inexperienced.

The management of internal conflicts in groups can also be highlighted as one of the skills exercised during the course. On many occasions, groups came to the teachers to bring problems such as a member who did not work, a member who wanted to do everything by himself, a member who wanted to fire himself to work with another group, etc. In all these cases, the teachers' guidance was always in the sense that the problems should be resolved as if they were acting in a company, i.e. targeting the company's interests and not the particular benefit of each member.

Eventually, some evolution on the three categories of competencies could be observed, which are, according to the Tuning Educational Structures in Europe (2007):

- as instrumental competencies (related to cognitive abilities, methodological capacities, technological and linguistic skills);

- interpersonal skills (related to processes of social interaction and co-operation, teamwork and ethical commitment);

- systemic competencies (the capacity for applying knowledge in practice, research skills, the ability to work autonomously, entrepreneurial spirit).

In addition, it is necessary to remark that in both semesters, no "unemployed" remained after the middle week, all fired students were from self-resignation and they were hired by other teams, so the traditional assessment by tests was not used.

\subsection{Evaluation of the course by the students}

In order to have a feedback from students about the methodology to which they had been submitted and to evaluate the acceptance of the method by students and also to understand to what extent the process contributes to the formation of the students, all the classes participated in a survey on the last day of the course in both 
semesters. The survey consisted of statements to be classified by Likert scale. The statements are described in Table 4. The answers to the survey are compiled in Figure 3 for 2014 and in Figure 4 for the 2015 experience.

The results of the surveys show that most students consider that, although it is an innovative and more motivating method that traditional one, it did not bring losses to their learning. Also, students find that the course has a workload equivalent to the traditional course, which may contradict the tendency to think that these methodologies relieve students' workload.

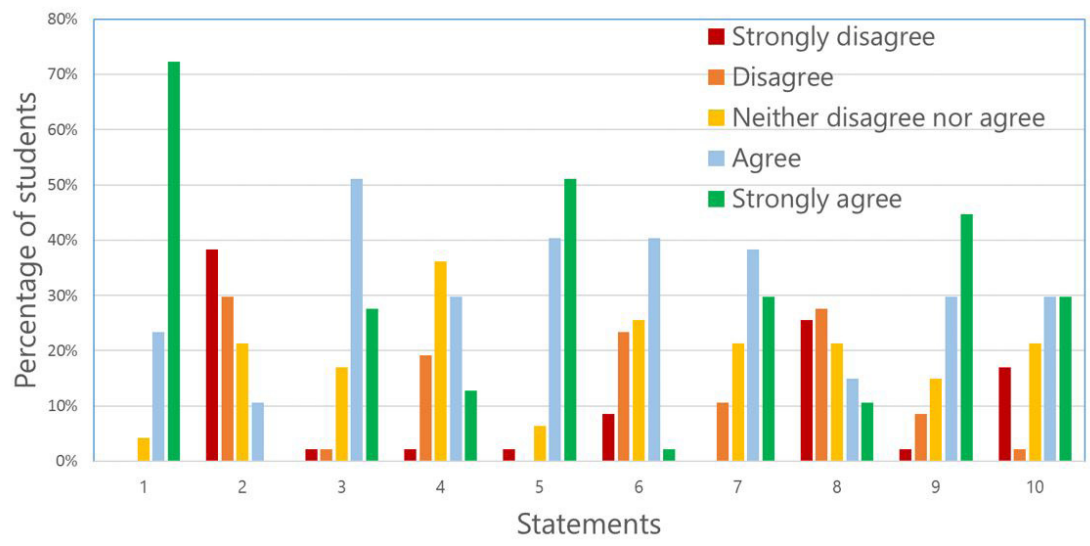

Figure 3. Compilation of the answers to the questionnaire in Table $4-2014$.

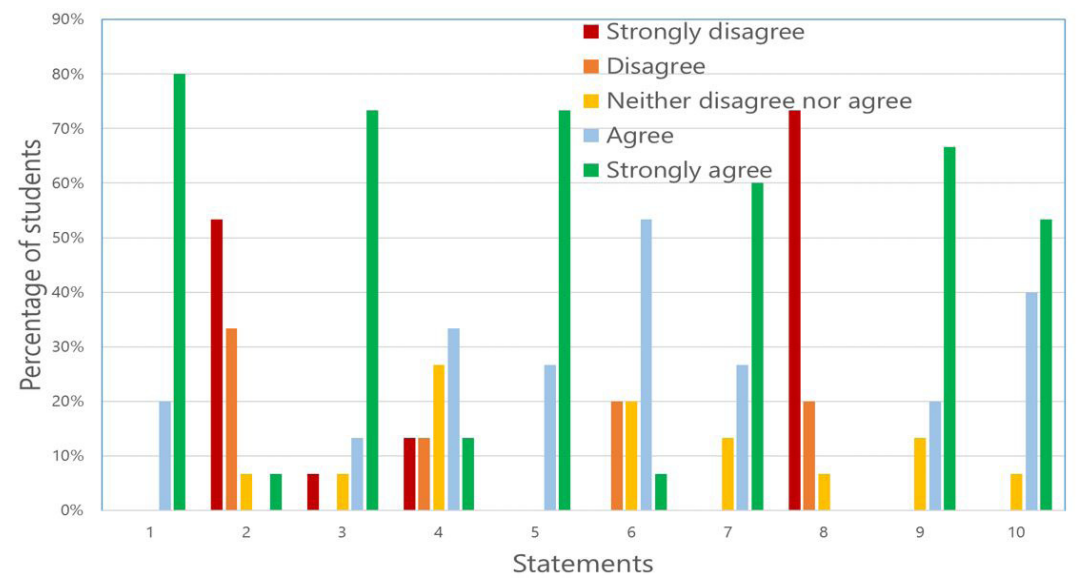

Figure 4. Compilation of the answers to the questionnaire in Table $4-2015$.

Analyzing the answers to statements 5 and 6 to the 2014 experience, it was observed that the students could learn better the items related to the subject of their work group than other matters, even considering that everybody had accessed all issues to produce their critical analysis in order to invest. This may be a weak point of this experience. On the other hand, in the 2015 experience, when the stakeholder groups were created, it can be observed that the sum of agree and strongly agree on responses changes from 91\% to 100\% (2014 to 2015) for the statement 5, but it increases from $42 \%$ to $60 \%$ (2014 to 2015) to the statement 6 , what clearly means that the creation of the stakeholder groups was effective in increasing the access to the subjects related to other groups.

Overall, students judged the assessment to be fair, and moreover, they would like other disciplines to use this innovative approach. 
Analyzing the responses to the statement 8, the sum of strongly disagree and disagree changed from 55\% to 93\% from 2014 to 2015. Probably, this change is related to the creation of the payback investment factor, which acted only in the second half of the 2014 experience, but in whole 2015.

As a final point, the perception that the competitive environment contributes to motivating the learning raised from 60\% to 93\% from 2014 to 2015, what can be seen as combined result of the changes made and may be also associated with the increase of the fairness of the assessment's criteria.

\section{Conclusions}

This paper reports the application of a PBL method in a discipline of the course of Chemical Engineering in two experiences carried out in 2014 and in 2015.

The rules created to conduct the experiment allowed the teachers to simulate a business environment so that the students felt as if they were acting in their professional lives.

The final set of rules, improved from the first to the second experience, increased student access to the contents of the discipline, enhanced the perception that the grading system is fair and declined attempts to circumvent the rules, also, the changes increased the motivation brought by competition between groups.

The solution of conflicts of interest and the attainment of goals and deadlines allowed students to develop important skills for their professional activities while they learned the content of the syllabus.

Finally, the authors believe they have achieved success in their objectives of facilitating the learning of the course content, and at the same time, they have driven students to acquire some of the necessary transversal competencies. So, this work definitively represents an alternative to teaching practice, especially for theoretical subjects, in which the experience of the teachers shows that the students are unmotivated with the traditional way of class.

The research contribution of this work is to show that the simulation of corporate environments and real competitive situations can motivate students to learn theoretical contents, putting them into practice and, at the same time, developing transversal skills important for the professional life, then, the set of rules and the model proposed may be readily adapted to other situations and, with minor changes, it is believed that the method can be applied to a wide variety of disciplines of any course.

\section{References}

Barnard, R. (1998). Classroom observation: some ethical implications. Modern English Teacher, 74), 49-55.

Borges, S., Monteiro, S., \& Quirino, M. G. (2011). Uma nova abordagem de ensino de Engenharia: Aprendizagem Baseada em Projetos (PjBL) na disciplina PSP1 do curso de Engenharia de Produção da UnB. In Anais do COBENGE: Congresso Brasileiro de Educação em Engenharia. Blumenau, SC.

Braghirolli, L. F., Ribeiro, J. L. D., Weise, A. D., \& Pizzolato, M. (2016). Benefits of educational games as an introductory activity in industrial engineering education. Computers in Human Behavior, 58, 315-324. http://dx.doi.org/10.1016/j.chb.2015.12.063.

Carvalho, C. V. (2012). Is game-based learning suitable for engineering education? In Proceedings of the lEEE Global Engineering Education Conference, EDUCON. Marrakech, Morocco. http://doi.org/10.1109/EDUCON.2012.6201140.

Cascini, G., Saliminamin, S., Parvin, M., \& Pahlavani, F. (2015). OTSM-TRIZ games: enhancing creativity of engineering students. Procedia Engineering, 131, 711-720. http://dx.doi.org/10.1016/j.proeng.2015.12.360.

Cunha, M. 1. (1998). Aportes teóricos e reflexao da prática: dos currículos universitários. Educación Superior y Sociedad, 9, 11-20.

Duch, B. J., Groh, S. E., \& Allen, D. E. (2001). Why problem based learning? A case study of institutional change in undergraduate education. In B. J. Duch, S. E. Groh \& D. E. Allen (Eds.), The power of problem-based learning (pp. 3-11). Sterling: Stylus.

Frame, 1., \& Canter, M. (2002). A menu of graduate skills - the specification of degree level skills for construction and surveying students a menu of graduate skills - the specification of degree level skills for construction and surveying students. In Proceedings of the 22nd FIG International Congress (pp. 1-14). Washington, DC.

Jollands, M., Jolly, L., \& Molyneaux, T. (2012). Project-based learning as a contributing factor to graduates' work readiness. European Journal of Engineering Education, 37(2), 143-154. http://dx.doi.org/10.1080/03043797.2012.665848.

Khrushchev, Y., Batseva, N., Fix, N., Chesnokova, 1., \& Khar'kovskaya, V. (2015). Business games in training engineering students. Procedia: Social and Behavioral Sciences, 206, 267-271. http://dx.doi.org/10.1016/j.sbspro.2015.10.023.

Kolmos, A., De Graaff, E., \& Du, X. (2009). Diversity of PBL- PBL Learning Principles and Models. In M. Begum. Research on PBL Practice in Engineering Education (Vol. 4, Chap. 2). Rotterdam, The Netherlands: Sense Publishers. http://doi.org/10.7771/1541-5015.1180.

Lima, R. M., Carvalho, D., Flores, M. A., \& Van Hattum-Janssen, N. (2007). A case study on project led education in engineering: students' and teachers' perceptions. European Journal of Engineering Education, 32(3), 337-347. http://dx.doi.org/10.1080/03043790701278599.

Mesquita, D., Lima, R. M., Flores, M. A., Marinho-Araujo, C., \& Rabelo, M. (2015). Industrial engineering and management curriculum profile: developing a framework of competences. International Journal of Industrial Engineering and Management, 6(3), $121-131$.

Moreno, M. L. R. (2006). De la evaluación a la formación de competencias genéricas: aproximación a un modelo. Revista Brasileira de Orientação Profissional, 7(2), 33-48. 
Nascimento, L. P. (2002). Elaboração de projetos de pesquisa. São Paulo: Cengage Learning.

Ribeiro, L. R. C. (2008). Aprendizagem Baseada em Problemas (PBL): uma experiência no ensino superior. São Carlos: EdUFSCar.

Roberto, L., \& Ribeiro, D. C. (2008). Aprendizagem Baseada em Problemas (PBL) na educação em engenharia. Revista de Ensino de Engenharia, 27(2), 23-32.

Salum, M. J. G. (1999). Os currículos de Engenharia no Brasil - estágio atual e tendências. In l. von Linsingen, L. T. V. Pereira \& C. G. Cabral. Formação do engenheiro: desafios da atuação docente, tendências curriculares e questões da organização tecnológica (pp. 34). Florianópolis: EDUFSC.

Singhal, A. C., Bellamy, L., \& McNeill, B. (1997). A new approach to engineering education (pp. 88). Arizona: Arizona State University.

Soares, F. O., Sepúlveda, M. J., Monteiro, S., Lima, R. M., \& Dinis-Carvalho, J. (2013). An integrated project of entrepreneurship and innovation in engineering education. Mechatronics, 23(8), 987-996. http://dx.doi.org/10.1016/j.mechatronics.2012.08.005.

Tuning Educational Structures in Europe (2007). Universities' contributions to the bologna process. Retrieved in 2 July 2017, from http://www.unideusto.org/tuningeu/

Walsh, P. (2007). Problem Based Learning in engineering. In Proceedings of the International Symposium for Engineering Education (pp. 97-101). Dublin, Ireland.

Yin, R. K. (2010). Estudo de caso: planejamento e métodos (4 ed). Porto Alegre: Bookman.

Received: Sept. 8, 2016

Accepted: June 5, 2017 